\title{
Why Just Two Parties? A Voting Game to Illustrate Duverger's Law
}

Keith Smith, University of the Pacific

ABSTRACT With the 2012 presidential elections approaching, student interest in (and frustration with) the US two-party system is likely to grow. Although many explanations exist for this phenomenon, their number and complexity often overwhelm students. This article describes an iterative game, designed for a single class session, that illustrates one of the major institutional explanations for the US two-party system-Duverger's Law. The game can also spur discussion of some of the major criticisms of the Law.

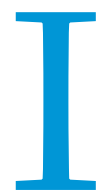
$\mathrm{n}$ the 1996 Simpsons' Treehouse of Horror episode "Citizen Kang," the aliens Kodos and Kang kidnap and create replicates of presidential candidates Bob Dole (R) and Bill Clinton (D). At a joint appearance just before the election, Homer exposes them as the "hideous space reptiles" they are. Kodos (or is it Kang?) states, "It's true. We are aliens, but what are you going to do about it? It's a two-party system. You'll have to vote for one of us." The audience murmurs its grudging agreement until someone says, "Well I believe I'll vote for a third party candidate." Kang (or is it Kodos?) retorts, "Go ahead: throw your vote away!" As the camera pans the audience Ross Perot punches out his straw hat. (Kang wins the election.)

Undergraduate students often feel like members of that crowdforced into a choice between the "lesser of two evils." I have yet to teach an introductory American politics class without at least one student expressing a longing for the choices offered by multiparty systems or the belief that a strong third party (especially an independent or moderate party) could solve many of the perceived problems in US politics. ${ }^{1}$ With the 2012 presidential election rapidly approaching, these concerns are likely to be more salient, and students are more likely to ask questions about why the United States has just two major political parties.

Political science offers several explanations for why the United States has a two-party system and why party systems vary across countries. Although these explanations generally fall into two categories-institutional explanations that focus on the structure of and rules governing a country's electoral system and sociological explanations that focus on the society's underlying social divisions (Ware 1995) - students frequently find the number of explanations, as well as their complexity, overwhelming. ${ }^{2}$ The scholarship of teaching and learning has recently emphasized active learning to solve problems like this (Angelo and Cross 1993; Kolb 1984). Through techniques such as role-playing games and simulations, students act out the course material, making its logic and processes their own, rather than remaining passive recipients. Active learning can help students retain more information as well as increase their enjoyment of class activities (Wedig 2010).

Keith Smith is an assistant professor in the department of political science at the University of the Pacific. He can be reached at ksmith4@pacific.edu.
This article describes an iterative game that explores the most frequently cited institutional explanation for why the United States has just two major political parties-Duverger's Law. The game illustrates how changing the rules about how parties win seats in government, specifically the electoral threshold, can affect the number of parties contesting the election. The game has two major learning objectives: First, by the end of the game and subsequent discussion, students should be able to explain Duverger's Law and its mechanisms. Second, students should be able to apply this knowledge to US politics and explain why it is difficult for third parties to succeed in the United States. The article proceeds in four parts. First, I briefly review the logic behind Duverger's Law. Second, I describe the game I developed to illustrate its operation to students. Third, I present some variations in the game play that have occurred. Finally, I discuss some of the game's limitations and possible extensions.

\section{DUVERGER'S LAW}

Duverger's Law claims "the simple-majority single-ballot system favors the two-party system" (Duverger 1954, 217). Countries that elect individual district representatives by plurality vote-often denoted as single-member, plurality districts (SMPD)-tend to have just two major parties. The corollary to the Law, which Riker (1982) calls Duverger's Hypothesis, is that "the simple-majority system with second ballot and proportional representation favors multipartyism" (Duverger 1954, 239). The core claim in the Law and the Hypothesis is that the number of parties in a political system is a function of the institutional rules governing its electoral process.

Lijphart (1995) identifies four primary dimensions to the institutional rules that affect the number of parties within a system: (1) the electoral formula (e.g., plurality, majoritarian, or proportional), (2) the district magnitude (the number of seats or candidates elected from a district), (3) the electoral threshold (the percentage of the vote required to win a seat), and (4) the assembly size (the total number of available seats in a legislature). Systems with plurality or majoritarian formulas, smaller district magnitudes, and higher thresholds tend to have fewer parties contesting elections. Plurality systems, as Duverger's Law predicts, tend to have just two electoral parties. 
Table 1

Representation in a PR and a Plurality System

\begin{tabular}{lcc|ccr}
\multicolumn{3}{c|}{ PR SYSTEM } & \multicolumn{3}{c}{ PLURALITY SYSTEM } \\
\hline Party & \% of Vote & \% of Seats & Party & \% of Vote & \% of Seats \\
\hline A & 45 & 45 & A & 45 & 100 \\
\hline B & 35 & 35 & B & 35 & 0 \\
\hline C & 20 & 20 & C & 20 & 0 \\
\hline
\end{tabular}

The Law is built on two effects: (1) a purely mechanical effect of denying representation to voters who do not vote for winning parties or candidates and (2) a psychological effect deriving from the feeling that voters "waste" their votes by casting a ballot for a party that does not have a reasonable chance of winning. Table 1 illustrates the difference in representation awarded to parties under a proportional representation (PR) system and a plurality system. In a PR system, where multiple candidates are elected from a single district, when a party meets a minimum threshold it wins roughly the same percentage of seats in the legislature as it did the popular vote. Thus, in this example, Party A, which received $45 \%$ of the vote, would win $45 \%$ of the seats from that district. Party B, which received $35 \%$ of the vote, would win $35 \%$ of the seats. Party C, which trailed with $20 \%$ of the vote, would still receive $20 \%$ of the seats. In contrast, in SMPD voting only one candidate is elected from the district, and the party receiving the most votes wins the seat-in this case Party A. Voters casting their ballots for Party B and Party C, despite constituting more than half of the electorate, are denied representation by the mechanics of the voting rule.

Under SMPD rules, Party B and Party C's supporters face a choice: vote sincerely for their preferred party and accept the certainty of defeat or vote strategically for another, less-preferred party in the hope that it will win. Rationally there is little incentive to continue voting for a losing party (though see Rapoport and Stone 2005; Riker 1982; Rosenstone, Behr, and Lazarus 1984), and psychologically it is difficult to vote for a party when you know it will lose. ("Go ahead: throw your vote away!") Thus, Duverger's Law predicts that the supporters of these two parties will vote strategically. The parties that remain will depend on the distribution of voters' policy preferences (Riker 1976).

Why, then, does the United States have just two major parties? Nearly all elections for public office in the United States are SMPD elections. We elect members of Congress from individual districts on the basis of plurality votes. State legislatures and local government officials are generally elected the same way. Even the presidential election can be thought of in SMPD terms. Although each state separately awards its electoral votes, the goal for political parties and their candidates is to win a simple majority in the Electoral College.

Note, Duverger's Law is not the sole reason why the United States has just two major political parties. Other theories also explain the existence of just two parties, and lively debate continues about their relative importance (see both Cox 1997 and Ware 1995 for review of these arguments). ${ }^{3}$ In the Variations section, I discuss some of these explanations in relation to particular situations that have arisen when playing this game.

\section{THE GAME}

The game described here is designed to be played in a single class session. Although I have used it in both lower-division American government surveys and in upper-division political parties courses, the game can easily be adapted to comparative politics courses. Playing time is between 30 to 40 minutes, depending on the number of students in the class, the number of voting rounds, and the method of voting used. Time is set aside at the end of the class to discuss the Law, its criticisms, and the students' reasons for behaving the way they did during the game play.

In this game, there is a single district from which representatives will be elected. Therefore, the electoral threshold determines the electoral formula, magnitude, and assembly size: as the threshold increases, the number of available seats declines and the system approaches a plurality formula. In the game, the instructor will gradually increase the number of votes required for election, which should cause the number of parties to decline as the game proceeds.

This game complements a useful simulation, also related to Duverger's Law, developed by Endersby and Shaw (2009). Important differences, however, exist between the two. First, Endersby and Shaw's focus is the act of strategic voting, which underlies the relationship in Duverger's Law between electoral rules and the number of parties. The game described here more directly illustrates this latter relationship. Second, in Endersby and Shaw's simulation, students privately respond to revealed information about candidates' policy positions without discussion or coordination. In this game, students play a more active role as they organize, campaign, and determine the number of parties.

\section{Participants and Roles}

The game involves the whole class. The instructor changes the rules to alter students' calculations about winning the game. All of the students vote, and a handful of self-selecting students act as elected representatives for their classmates. If you choose to have students cast ballots to vote, then it is helpful to designate one student at the outset as the class's "elections official." That student distributes ballots and counts the votes after each election. Depending on the number of students in a class, this student may not otherwise participate in the game.

\section{Materials}

The game generally works best if there is some incentive for being in the winning coalition. While it is possible to run the game without any reward, students are more likely to engage in the process when there is clearly something to be gained at the end. I often have a number of nondivisible goods available for students. ${ }^{4}$ Alternatively, I have made the day's participation grade a function of being in the winning coalition.

A board on which to record the number of votes required to win a seat, the number of votes received by each candidate, and the number of winning candidates is also useful. After the game, I use these numbers in the discussion of what was possible under each round's electoral threshold and how students made their voting decisions.

Finally, if ballots are used in the elections, then adequate scraps of paper for the ballots and pencils for students to record their votes are needed. 


\section{Setting up the Game}

Before coming to class, students will have read some material on why the United States has a two-party system. The exact readings depend on the level of the course. For a lower-division course, I rely on material in the textbook I am using that semester. For an upper-division course, I often assign Riker (1982) and Ware (1995, 184-212). Thus, if they have done the reading, students have some familiarity with major theories explaining why there are just two parties in the United States before playing the game.

I begin the class by having students move the chairs to the sides of the room. If I am in a room where the desks or chairs cannot be moved, then I take the class somewhere where their movement is not obstructed. To break up any cliques that have formed in the class, I ask the students to take 10 to 20 steps in any direction.

\section{Playing}

At the beginning of the game, I tell the students that for the day I will be playing the role of a dictator distributing a number of goods to curry support with the population. The goods are things that the students want (sometimes at this point I show students examples of the goods), but they are scarce and nondivisiblethere are not enough items for everyone in the class, and it is not possible to break the items into pieces so that everyone can get something. diate collapse to just two groups, is discussed later). Sometimes students need to be encouraged to campaign and bargain for votes or find a group that will allow them to be represented on the council. When the time is up, I hold the election.

Students can vote by secret ballot, by raising their hands, or by location. There are trade-offs to the method of voting. Voting by ballot takes longer as the votes must be counted but is more likely to introduce strategic voting as students can more easily defect without any sanction from their peers. Voting by raising hands or by location (i.e., by simply counting the members of the groups that have formed) can introduce another dimension-geography or group loyalty-to the voting beyond competitive self-interest (more on this in the Variations section). Each of these trade-offs can be useful in the postgame discussion of why people joined parties and potentially why some parties persisted despite not having enough votes to win representation.

After the results are tallied, but before the governing council has been seated, I void the election results. My stated reason for doing this is that it is possible to have a tie vote on the governing council because there is an even number of representatives. Therefore, the council may deadlock in its decision about how to allocate the goods. (I usually acknowledge that this was my mistake in setting up the rules for the election.) Having voided the election, I increase the number of votes required to win a seat so that an odd number of representatives should be elected. Continuing

\section{A second round of campaigning and voting occurs, but before the council is seated I throw out the results for an arbitrary reason (e.g., "My astrologist told me this is a bad number for a governing council" or "Aid donors object to the composition of this council") and increase the vote requirement.}

Because I am a benevolent dictator, I explain, they will participate in the decision about how the goods are distributed. As the transaction costs for including everyone in the decision are too high (a potential source of conversation after the game has been played), I will form a governing council of student representatives. The council members will then negotiate the distribution of the goods to the class. To facilitate this process, I will hold an election for the students to pick their representatives.

Next, I define the electoral threshold-the number of votes someone must win to gain a seat on the council. Although I do not tell the students, this threshold will change several times during the game. When possible, the first electoral threshold allows a large, even number of students to win election (doing so lets me invalidate the election results as explained later; see the Appendix for help with this task). For example, in a class of 25 students, at least four votes are required to win representation on the council. If the students behave as expected (i.e., rationally to maximize the number of parties), this requirement should result in six parties-five parties with four members each and one party with five members.

Students have three to five minutes to organize themselves to contest the election, including deciding who will be the representatives. Usually, students simply clump together on the basis of proximity, forming groups large enough to meet the minimum voting requirement (although an important variation, an imme- the earlier example, with 25 students I now require five votes to win a seat, which should result in five representatives.

The game play continues as before. A second round of campaigning and voting occurs, but before the council is seated I throw out the results for an arbitrary reason (e.g., "My astrologist told me this is a bad number for a governing council" or "Aid donors object to the composition of this council") and increase the vote requirement. I repeat the process one to three more times depending on class time, size, and the mood of the students. Eventually, to mimic the conditions of Duverger's Law (and often feigning frustration with the whole process), I state that whoever receives the most votes in the next round of voting will determine the distribution of the goods. After this final round of voting, the winning coalition is declared, and the goods are distributed according to its preference (usually just its members).

At the same time, the students return to their seats and we discuss the mechanics of the game as well as their thinking throughout the voting process. First, we review the formal logic of their strategies and why they formed the groups they did. During this discussion, I refer to the different thresholds used in the game, which were recorded on the board, and the different outcomes they created. Example discussion questions include: Why did you form that many parties? Why not more? How many could have been formed at each stage of the game? Why not more? What are the formal limits? 
Table 2

Student Evaluations of the Game

\begin{tabular}{lcc} 
CONCEPT & MEAN RATING & PTM \\
\hline Single-member, plurality district & 4.25 & $85 \%$ \\
\hline Duverger's Law & $(0.18)$ & \\
\hline Mechanical effect & 4.46 & $89 \%$ \\
& $(0.12)$ & \\
\hline Psychological effect & 4.25 & $85 \%$ \\
& $(0.15)$ & \\
\hline
\end{tabular}

Notes: Students were asked: "How useful was the game in helping you understand each of the following concepts" with answers ranging from 1 (very little) to 5 (a lot). The survey was administered after the game was played in the spring 2011 semester. $N=28$. Standard errors are reported in the parentheses.

We also use their experiences in the game to explore why it is difficult for third parties to succeed in US politics. Here, the discussion focuses on their motivations, feelings, and behavior as the electoral threshold changed. Example questions include: If you changed parties during the game, why? Why not stay in your initial group? Why did you join one party and not another? What was the basis of your decision? If you remained in a party after it could no longer win, what was your motivation? Why didn't you join another party?

Over the years, I have found this game a useful tool to help students understand the influence of institutional rules on party systems. Indirectly, students report that the game helps them better understand the key concepts. Table 2 shows summary measures for student evaluations of the game. The students were asked to indicate how useful the game was in helping them understand each of the four concepts in table 2. The possible responses ranged from 1 (very little) to 5 (a lot). The mean answer for each concept fell between 4.25 and 4.46. The percent-to-max (PTM) rating (the percentage of total points possible observed) for each concept was at least $85 \%$ in each case. More directly, I find that students more clearly and fully answer questions surrounding Duverger's Law and its impact in those classes when I have used the game than in those when I have not. 5

\section{VARIATIONS}

Although the game play usually proceeds as described, two variations are worth mentioning. The first-an immediate or almost immediate collapse to two parties when the rules allow for multiple parties-is relatively uncommon. The second-the persistence of third parties in the face of defeat-is more common. Both of these variations illustrate an important criticism of Duverger's Law.

The primary alternative to Duverger's Law is the sociological view that the number of parties in a political system is a function of the number of salient, underlying social cleavages (e.g., religion, class, ethnicity, and labor groupings) rather than the formal rules governing elections. The claim is that where we see more social cleavages we should see more major parties, and where we see fewer cleavages we should see fewer parties. Most observers hold that the United States has a dualist culture-the major issues surrounding government tend to be cast as either/or propositions built on consensus about a set of liberal values (c.f. Hartz 1955). Thus, advocates of the sociological view hold, the US political system cannot sustain more than two parties.

In the context of this game, there is generally just one dimension to the political conflict-who will receive the goods and who will not. No additional, salient cleavages exist to support conflict among groups. Thus, although relatively uncommon, on occasion the class has within the first two rounds divided itself into two parties (a majority and a minority party) when the rules allowed for more. Sometimes the students do so from a more complex strategic calculation. Recognizing that they will need a majority on the governing council to determine the final allocation of goods, the students short-cut the process and form a majority in the initial rounds of voting. (Usually this coordination results in the opposite, with students splitting up large groups to win as many seats on the council as possible.) At other times the students simply profess that they do not see the need for additional parties.

If this quick collapsing to two parties happens, sustaining the game is difficult. In the absence of alternative cleavages, once students discover either logic they tend not to go back to the behavior predicted by Duverger's Law. At this point, then, it is helpful (a) to demonstrate the logic of Duverger's Law using something akin to table 1 and then (b) to explore their reasons for forming just two parties when the electoral rules would allow them to form more. I have found these discussions to be among the most fruitful for students. ${ }^{6}$

The second variation is that smaller parties may continue to exist after they can no longer win representation on the governing council. Sometimes this continuance happens because students do not care about getting one of the goods. In a postgame survey, for example, students were asked to indicate how much they cared about who won. The mean response, with 1 being not at all and 5 being a lot, was just $2.5(n=28$, S.E. $=0.22)$. As such, students may find the costs of forming new parties too great relative to the benefits of being in the winning coalition (i.e., it is just too much effort to move to another part of the room). Alternatively, sincere group loyalties, such as those springing from personality conflicts or fraternity rivalries, may prevent the combining of parties. Finally, sometimes students may simply choose to be iconoclastic or difficult.

Each of these reasons, among others, demonstrates at least two points that can be brought out in postgame discussion. First, the pure logic of Duverger's Law does not always hold when real people participate in real politics. Although we frequently assume that rational self-interest causes people to form larger and larger parties as the voting requirements to win representation increaseand not to maintain small, third parties-the incentives to do so may not be strong enough. Second, parties can persist even in the face of sure defeat when other dimensions to politics are introduced (i.e., additional social cleavages). What matters is the relative importance that individuals apply to maintaining those cleavages versus being in the winning coalition.

\section{LIMITATIONS AND EXTENSIONS}

This section discusses a challenge related to the game play, a limitation of the game, and some possible extensions. The challenge is that the calculation of voting requirements can be tricky and, to the extent possible, needs to be determined before the class begins. (To assist in planning, appendix A presents the voting requirements that produce unique outcomes in terms of the number of 
winning parties for class sizes ranging between 15 and 60 students.) Moreover, it is not always possible to start with an even number of parties. For example, to start with an even number of parties in a class of 15 students the dictator needs to require six votes for a student to win a seat on the governing council. Just two winning parties are possible with this requirement, leaving only two rounds of game play. In this case, an alternative reason for throwing out the election results should be determined at the start of the game.

One limitation of the game is class size. Although I have used this game in a variety of settings-large and small classes at public and private institutions-the game is best suited to a class of 20 to 40 students. Larger classes allow more voting rounds but also introduce coordination problems. If the class is too large (e.g., $60+$ students), the process of selecting representatives, canvassing, and voting becomes difficult and time consuming. Conversely, if the class is too small (e.g., less than 10 students), the voting cannot be sustained for more than two or three rounds. Medium-sized classes minimize the trade-offs between extended game-play and coordination costs. the world differ and, more specifically, why the United States has just two major political parties-Duverger's Law. Although considerable controversy over the influence of the Law exists, the game allows some of those criticisms to come to the fore. The game lets students act out, and therefore better internalize, the logic behind a principal argument for the US two-party system and why third parties rarely play a significant role in the outcomes.

\section{NOTES}

1. Given Peter Ackerman's efforts with the Americans Elect party/nonparty in 2011-12 and Unityo8 and the media attention given to potential third party candidates during presidential elections, this hope is clearly not confined to just undergraduates. (See also Matt Miller's 2011 campaign for a third party candidate in the Washington Post.)

2. During the spring 2011 semester, for example, before playing this game but after students had (supposedly) read material on the US two-party system, I asked students in my department's introductory US government course to explain why there are just two major political parties in the United States. Despite reading about how electoral institutions constrain the number of parties, very few-just three students in a class of 28-were able to identify Duverger's Law or any other institutional influence as a cause of America's two-party

\section{As the 2012 presidential election nears, student interest in (and expressed dissatisfaction with) the US party system is likely to grow. The game described here engages that interest to explore one of the primary explanations for why party systems around the world differ and, more specifically, why the United States has just two major political parties-Duverger's Law.}

Although the game is principally designed for exploring why the United States has a two-party system, it can also introduce additional discussion topics. One possible extension is to explore the nature and role of parties within a political system. Although I have referred to the groups students form to contest the elections as "parties," it is not necessary to do so during gameplay. During the postgame class discussion, the nature and role of these groups in facilitating the electoral process can be explored (e.g., Why did you form these groups? What role did they play in the game?). The students' actions can be compared to Downs's (1957, 34) classic definition of a party: "a team of individuals seeking to control the governing apparatus by gaining office in an election."

If you incorporate an elections official in the game, another extension is to examine that person's role in its process and outcome. In most US states, the position of chief elections officer is a partisan office, meaning the person who is obligated to ensure the integrity of the electoral process has a partisan stake in its outcome. Sometimes this dual role creates tensions, both in the official's behavior toward individual candidates as well as the ability of third parties to gain ballot access. ${ }^{7}$ The students, therefore, can use their experience to explore the appropriate role of partisan officials in elections administration: What impact did the elections official have on the outcome? Did it make a difference that the person voted for one of the candidates? Should the elections official be partisan? What would affect your level of confidence in the elections official?

As the 2012 presidential election nears, student interest in (and expressed dissatisfaction with) the US party system is likely to grow. The game described here engages that interest to explore one of the primary explanations for why party systems around system. Moreover, the students' most frequently cited explanations-the major parties' broad platforms $(39 \%)$, the persistence of the two-party system over time (e.g., "It's always been that way") (36\%), and third parties' lack of necessary resources $(32 \%)$-are consequences of the institutional setting rather than independent influences.

3. Given the many plausible explanations, many consider the US two-party system to be an over-determined outcome.

4. A personal favorite is a box of goodies from the novelty company Archie McPhee, www.mcphee.com. Candy tends not to work as students (a) often do not want any (or have assorted food allergies) and (b) try to bargain so as to split the candy such that it is possible for everyone to end up with something at the end.

5. This statement is based on a number of years experience using the game. Admittedly, in an ideal world, I would have the subject scores from classes when include the game and when I do not. In the context of a small, liberal arts college, where only one section is offered per semester and the teaching responsibility is shared among multiple faculty members, gathering such data is a multiyear endeavor. As such, I have not yet gathered the necessary data to document this claim directly.

6. Once, students professed that because they grew up in a political system dominated by just the Republican and Democratic parties they could not conceive of political conflict except in terms of two parties.

7. See, for example, the controversies surrounding Florida Secretary of State Katherine Harris and Ohio Secretary of State Ken Blackwell's roles in President Bush's 2000 campaign and Ralph Nader's 2007 lawsuit against the Democratic National Committee.

\section{REFERENCES}

Angelo, Thomas A., and K. Patricia Cross. 1993. Classroom Assessment Techniques: A Handbook for Faculty, 2nd ed. San Francisco: Jossey-Bass.

Cox, Gary W. 1997. Making Votes Count: Strategic Coordination in the World's Electoral Systems. Cambridge: Cambridge University Press.

Downs, Anthony. 1957. An Economic Theory of Democracy. New York: Harper and Row.

Duverger, Maurice. 1954. Political Parties. London: Methuen. 
Endersby, James W., and Kelly B. Shaw. 2009. "Strategic Voting in Plurality Elections: A Simulation of Duverger's Law.” PS: Political Science \& Politics 42 (2): 393-99.

Hartz, Louis. 1955. The Liberal Tradition in America: An Interpretation of American Political Thought Since the Revolution. New York: Harcourt, Brace.

Kolb, David A. 1984. Experiential Learning: Experience as the Source of Learning Development. Englewood Cliffs, NJ: Prentice Hall.

Lijphart, Arend. 1995. Electoral Systems and Party Systems: A Study of Twenty-Seven Democracies, 1945-199o. Oxford: Oxford University Press.

Miller, Matt. 2011. "Why We Need a Third Party." The Washington Post. September 25 .

Rapoport, Ronald B., and Walter J. Stone. 2005. Three's a Crowd: The Dynamic of Third Parties, Ross Perot, and Republican Resurgence. Ann Arbor: University of Michigan Press.

Riker, William H. 1976. "The Number of Political Parties: A Reexamination of Duverger's Law.” Comparative Politics 9 (1): 93-106.

- 1982. "The Two-Party System and Duverger's Law: An Essay on the History of Political Science." The American Political Science Review 76 (4): 753-66.

Rosenstone, Steven J., Roy L. Behr, and Edward H. Lazarus. 1984. Third Parties in America: Citizen Response to Major Party Failure. Princeton, NJ: Princeton University Press.

Ware, Alan. 1995. Political Parties and Party Systems. Oxford: Oxford University Press.

Wedig, Timothy. 2010. "Getting the Most from Classroom Simulations: Strategies for Maximizing Student Learning Outcomes." PS: Political Science E Politics 43 (3): $547-55$.

\section{APPENDIX: Voting Requirements with Unique Outcomes}

STUDENTS

\begin{tabular}{|c|c|}
\hline 15 & $2,3,4,6,8$ \\
\hline 16 & $2,3,4,5,6,9$ \\
\hline 18 & $2,3,4,5,7,10$ \\
\hline 20 & $2,3,4,5,6,7,11$ \\
\hline 21 & $2,3,4,5,6,8,11$ \\
\hline 22 & $2,3,4,5,6,8,12$ \\
\hline 24 & $2,3,4,5,7,9,13$ \\
\hline 25 & $2,3,4,5,6,7,9,13$ \\
\hline 26 & $2,3,4,5,6,7,9,14$ \\
\hline 27 & $2,3,4,5,6,7,10,14$ \\
\hline 28 & $2,3,4,5,6,8,10,15$ \\
\hline 30 & $2,3,4,5,6,7,8,11,16$ \\
\hline 32 & $2,3,4,5,6,7,9,11,17$ \\
\hline 33 & $2,3,4,5,6,7,9,12,17$ \\
\hline 34 & $2,3,4,5,6,7,9,12,18$ \\
\hline 35 & $2,3,4,5,6,8,9,12,18$ \\
\hline 36 & $2,3,4,5,6,7,8,10,13,19$ \\
\hline 38 & $2,3,4,5,6,7,8,10,13,20$ \\
\hline 39 & $2,3,4,5,6,7,8,10,14,20$ \\
\hline 40 & $2,3,4,5,6,7,9,11,14,21$ \\
\hline 42 & $2,3,4,5,6,7,8,9,11,15,22$ \\
\hline 44 & $2,3,4,5,6,7,8,9,12,15,23$ \\
\hline 45 & $2,3,4,5,6,7,8,10,12,16,23$ \\
\hline 46 & $2,3,4,5,6,7,8,10,12,16,24$ \\
\hline 48 & $2,3,4,5,6,7,9,10,13,17,25$ \\
\hline 49 & $2,3,4,5,6,7,8,9,10,13,17,25$ \\
\hline 50 & $2,3,4,5,6,7,8,9,11,13,17,26$ \\
\hline 51 & $2,3,4,5,6,7,8,9,11,13,18,26$ \\
\hline 52 & $2,3,4,5,6,7,8,9,11,14,18,27$ \\
\hline 54 & $2,3,4,5,6,7,8,10,11,14,19,28$ \\
\hline 55 & $2,3,4,5,6,7,8,10,12,14,19,28$ \\
\hline 56 & $2,3,4,5,6,7,8,9,10,12,15,19,29$ \\
\hline 57 & $2,3,4,5,6,7,8,9,10,12,15,20,29$ \\
\hline 58 & $2,3,4,5,6,7,8,9,10,12,15,20,30$ \\
\hline 60 & $2,3,4,5,6,7,8,9,11,13,16,21,31$ \\
\hline
\end{tabular}

Notes: Numbers in italics generate an odd number of parties. Omitted class sizes mimic the outcomes for the next lowest class size-e.g., a class with 17 students generates the same outcomes as a class with 16 students, a class with 19 students generates the same outcomes as one with 18 students, etc. 